\title{
FRATURA SALTER HARRIS TIPO I TIBIAL EM NOVILHA - RELATO DE CASO
}

Tiago da Cunha Peixoto ${ }^{1}$, Danielle Nascimento Silva ${ }^{2}$, Roberto Viana Menezes ${ }^{3}$, Anna Fernanda Machado Sales da Cruz Ferreira ${ }^{3}$, Vitor Santiago de Carvalho ${ }^{3}$

${ }^{1}$ Professor Doutor do Departamento de Anatomia Patologia e Clínicas Veterinárias da Universidade Federal da Bahia (UFBA), Salvador, BA, Brasil. Autor para correspondência. (tiagocpeixoto@yahoo.com.br).

${ }^{2}$ Mestranda do Programa de Pós-graduação em Ciência Animal nos Trópicos da UFBA, Salvador, BA, Brasil.

${ }^{3}$ Médicos Veterinários do Centro de Desenvolvimento da Pecuária (CDP) da UFBA, Santo Amaro, BA, Brasil.

Recebido em: 08/09/2015 - Aprovado em: 14/11/2015 - Publicado em: 01/12/2015 DOI: http://dx.doi.org/10.18677/Enciclopedia_Biosfera_2015_163

Fraturas ósseas decorrem da submissão do osso a estresse de curta duração. Em ruminantes, acometem com maior frequência animais jovens, principalmente, os ossos metacarpo e metatarso. Fratura Salter Harris tipo I em bovinos são pouco descritas na literatura. Objetivou-se relatar um caso de fratura Salter Harris tipo I em uma novilha Gir, oriunda do município de Terra Nova, Bahia. O animal foi atendido no CDP-UFBA, com histórico de fratura após resvalar. Ao exame físico, observaramse claudicação do membro pélvico esquerdo (MPE) devido à fratura completa exposta da tíbia associada à intensa hemorragia. Os exames radiográficos diagnosticaram fratura de Salter Harris tipo I. O MPE foi imobilizado com gesso sintético. Devido ao peso e comportamento inquieto do animal, houve afrouxamento do gesso e perda da imobilidade. $O$ animal adotou decúbito permanente e devido ao agravamento do quadro clínico e prognóstico desfavorável optou-se pela eutanásia. À necropsia, verificaram-se marcado aumento de volume do MPE, sobretudo, na região da articulação tíbio tarsal, com grande área de laceração cutânea. Notou-se exposição completa da extremidade distal da diáfise e metáfise tibial (fratura transversa completa através da placa de crescimento/linha de fechamento epifisário). Ao corte do tecido subcutâneo e musculatura regional, observaram-se hematoma subcutâneo em organização e acentuada miosite necrohemorrágica localmente extensa, respectivamente. O diagnóstico foi estabelecido com base nos dados clínico-epidemiológicos e confirmado pelos exames radiográficos. Adicionalmente, a avaliação necroscópica e histopatológica corroborou o diagnóstico radiográfico, confirmou o caráter necro-hemorrágico das lesões nos tecidos adjacentes secundárias à fratura.

PALAVRAS-CHAVE: Bovinos, Lesões ósseas, Patologia 


\title{
SALTER HARRIS TYPE I FRACTURE OF THE DISTAL TIBIA IN A CALF - CASE REPORT
}

\begin{abstract}
Bone fractures are result of the submission of the bone to stress short-lived. In ruminants affect more frequently young animals especially the metacarpal and metatarsal bones. In cattle, Salter Harris type I fracture are rarely described in the literature. This study aimed to report a case of Salter Harris type I fracture in a calf from a property in Terra Nova city, Bahia. The animal was treated at the CDP-UFBA, with a history of fracture after slipping. At physical examination, it was observed on the left hind limb (LHL) complete exposed fracture with heavy bleeding. Radiographic examinations diagnosed Salter Harris type I fracture. The LHL was immobilized with synthetic gypsum. Due to its weight and restless behavior, there was loosening of plaster and loss of immobility. The animal adopted permanent decubitus, and due to the worsening of clinical symptoms and poor prognosis, it was decided for euthanasia. At necropsy, there were marked increase of LHL volume, especially at the region of the tibial tarsal joint, with large area of skin laceration. It was observed complete exposition of the distal tibial metaphysis and diaphysis (full transverse fracture through the growth plate). Cutting the subcutaneous tissue and muscles regionally, there were subcutaneous hematoma in organization and myositis sharp locally extensive necro-hemorrhagic respectively. The diagnosis was based on clinical and epidemiological data and confirmed by radiographs. In addition, autopsy and histopathological evaluation corroborated the radiographic diagnosis confirmed the necro-hemorrhagic character of damage to adjacent tissues secondary to fracture.
\end{abstract}

KEYWORDS: Bone lesions, Cattle, Pathology

\section{INTRODUÇÃO}

Fraturas ósseas decorrem da submissão do osso a estresse de curta duração (SANTILI et al., 2010). Em ruminantes, fraturas são relativamente frequentes (SPADETO JÚNIOR et al., 2010), sobretudo, aquelas localizadas nos membros de animais jovens as quais, em geral, são relacionadas a traumatismos durante o parto distócico, manuseio ou pisoteio da genitora (MULON, 2013). Essas lesões são observadas, principalmente, no metacarpo e metatarso (em cerca de $50 \%$ dos casos) e, em menor frequência, por fraturas tibiais (12\%), rádio/ulnares $(7 \%)$ e umerais (menos de 5\%) (REILLY et al., 2005; ANDERSON \& ST JEAN, 2008). Por outro lado, fraturas no fêmur, falanges e esqueleto axial (mandíbula, vértebras, costelas e pélvis) têm sido relatadas com frequência ainda menor (STEINER \& ANDERSON, 2009).

Alguns autores acreditam que grande parte dos casos de fraturas ósseas em bovinos evolui sem atendimento veterinário, sendo os animais fraturados destinados ao abate pelo pecuarista, por alegarem ser inviável o tratamento do animal, devido ao alto custo, muitas vezes, superior ao valor do animal (CÂMARA et al., 2014). É provável que, na Bahia esse hábito dos proprietários seja semelhante. Além disso, a eutanásia de animais de grande porte acometidos por fraturas ósseas é a alternativa adotada, na maioria das vezes, pelo proprietário, sobretudo, na ocorrência de fraturas em ossos longos (VECHIATO et al., 2009), ou seja, a ocorrência de fraturas em bovinos provavelmente vem sendo subestimada, bem como as perdas econômicas para a pecuária. 
As fraturas de origem fisária são observadas com maior frequência em indivíduos jovens, sendo a lesão no homem mais relatada em crianças (SANTILI et al., 2010) e adolescentes (PODESZWA \& MUBARAK, 2012) e, em medicina veterinária, em animais jovens devido a fraqueza da fise antes da fusão óssea (JOHNSON \& DURBIN, 2012). SALTER e HARRIS (1963) classificaram as fraturas da placa de crescimento baseada na natureza da linha de fratura e as estruturas adjacentes envolvidas, dividindo-as em cinco grupos (tipo I, II, III, IV e V). Na fratura Salter Harris tipo I há separação completa da fise; na do tipo II a linha de fratura envolve toda a fise e uma parte da metáfise; na do tipo III ocorre comprometimento da superfície articular que se estende através da fise; já a do tipo IV incluem fraturas através da epífise, em toda a fise e através da metáfise, geralmente, envolvendo as superfícies articulares e, por fim a do tipo $\mathrm{V}$ são fraturas compressivas envolvendo a fise óssea.

CÂMARA et al. (2014) ressaltam que, embora haja descrições na literatura acerca da terapêutica adotada em casos de fraturas induzidas experimentalmente (SPADETO JÚNIOR et al., 2010), bem como em alguns casos de fraturas de ocorrência espontânea (MARTINS et al., 2001; VECHIATO et al., 2009), publicações que abordem a caracterização das fraturas em animais de produção ainda são infrequentes. Além disso, casos de fratura Salter Harris tipo I em bovinos são pouco descritos na literatura e no estado da Bahia a prevalência de doenças em bovinos ainda são muito pouco conhecidas. Objetivou-se com esse estudo descrever um caso de fratura Salter Harris tipo I tibial em uma novilha no estado da Bahia.

\section{RELATO DE CASO}

Em dezembro de 2014, uma novilha, da raça Gir de alto valor zootécnico (recém-campeã de exposição), com dois anos de idade e $500 \mathrm{~kg}$, oriunda de uma propriedade do município de Terra Nova, BA foi atendida na Clínica de Ruminantes do Centro de Desenvolvimento da Pecuária da Escola de Medicina Veterinária da Universidade Federal da Bahia (CDP-UFBA), com histórico de fratura após resvalar na propriedade. Após a chegada do animal, observou-se claudicação do membro pélvico esquerdo (MPE), o qual exibia fratura completa exposta da tíbia associada à intensa hemorragia.

Após cessada a hemorragia da lesão, realizou-se avaliação radiográfica nas incidências lateromedial, dorsoplantar, dorsolateral-plantaromedial oblíqua e dorsomedial-plantarolateral do MPE, o que permitiu o diagnóstico radiográfico de fratura exposta, do tipo Salter Harris I na epífise distal da tíbia do MPE (Figura 1A). Em adição, observaram-se no hemograma hiperfibrinogenemia e leucocitose com desvio a esquerda regenerativo. Em virtude do realinhamento da fratura ser difícil e pela exposição tíbial, o animal foi mantido em decúbito dorsal e o MPE foi suspenso por uma talha. Ato contínuo, o MPE foi imobilizado com gesso sintético Scotchcast ${ }^{\circledR}$ (Figura 1B). Instituiu-se terapêutica alopática com administração de antibiótico a base de ceftiofur $(1,0 \mathrm{mg} / \mathrm{kg}$, IM) por 8 dias, fenilbutazona associada a dexametasona $(0,2 \mathrm{~mL} / 100 \mathrm{~kg}$, IV) por 4 dias. 

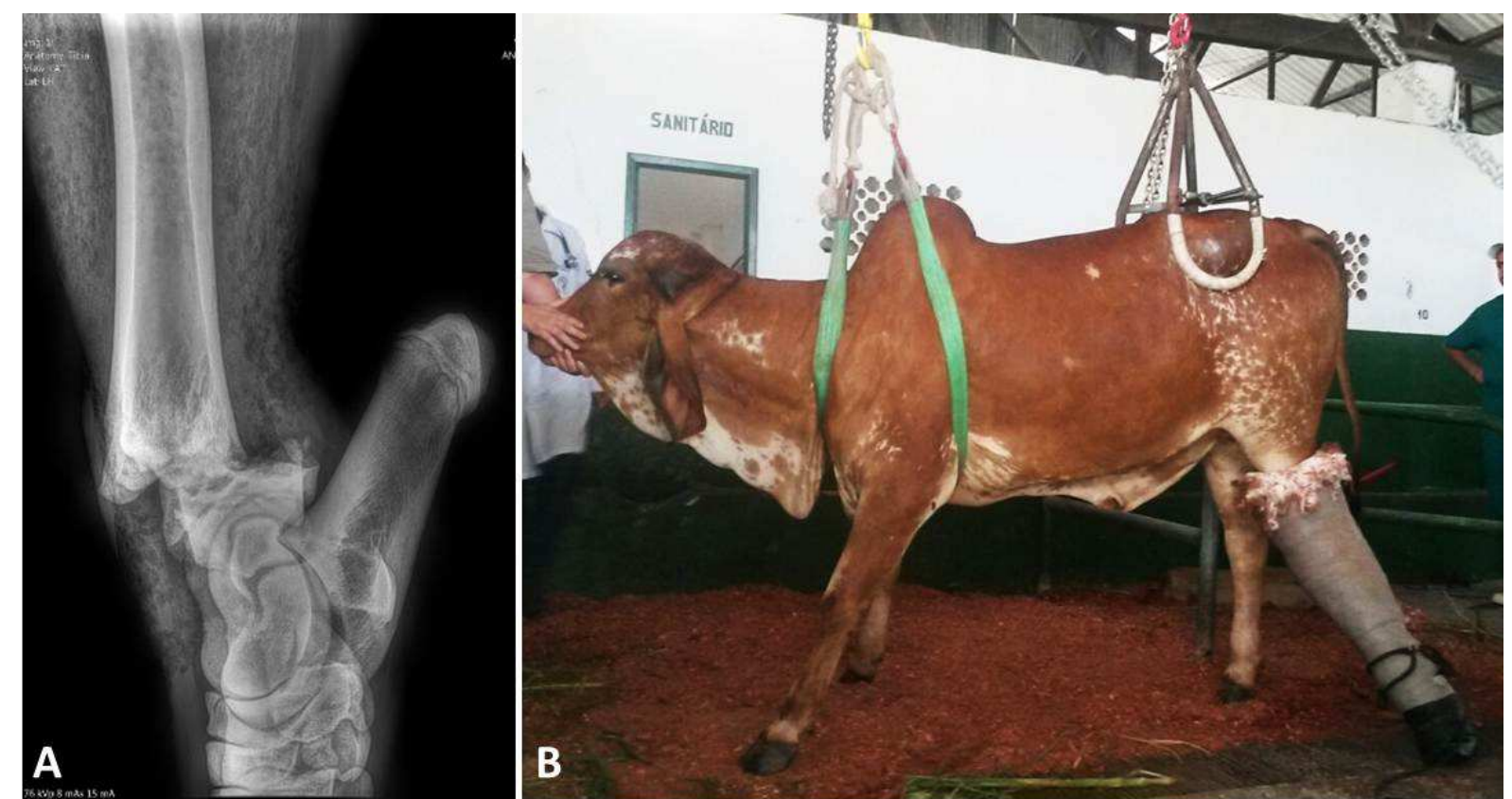

FIGURA 1: Fratura Salter Harris tipo I tibial em novilha. A. Exame radiográfico lateromedial da articulação tíbio tarsal esquerda, revelando fratura transversa completa através da placa de crescimento da tíbia. B. Bovino, fêmea, da raça Gir, com dois anos de idade e $500 \mathrm{~kg}$, após a imobilização do membro posterior esquerdo com gesso sintético. (Fonte: arquivo pessoal).

No quarto dia após o internamento do bovino, adotou-se o uso de protetores de mucosa gástrica a base de omeprazol e sucralfato $(4,0 \mathrm{mg} / \mathrm{kg}$ e $2,0 \mathrm{mg} / \mathrm{kg}$, respectivamente, VO), por 4 dias. Devido ao grande peso corporal $(500 \mathrm{~kg})$ e comportamento agitado do animal, detectou-se afrouxamento do gesso, perda da imobilidade e dificuldade de permanência em estação durante algumas horas do dia.

O animal adotou decúbito permanente e, como consequência, desenvolveu diversas escaras de decúbito e, após sete dias internado, devido à baixa eficiência na consolidação da fratura, agravamento do quadro clínico e prognóstico desfavorável o proprietário optou pela eutanásia. Imediatamente após a morte, o cadáver foi encaminhado ao Setor de Patologia do CDP para ser necropsiado.

À necropsia, verificaram-se marcado aumento de volume do MPE, sobretudo, na região da articulação tíbio tarsal, com grande área de laceração cutânea na face medial medindo $7,0 \times 5,5 \mathrm{~cm}$, de bordas irregulares necróticas castanhoavermelhado; notou-se ruptura da cápsula articular e exposição completa da extremidade distal da diáfise e metáfise tibial (fratura transversa completa através da placa de crescimento/linha de fechamento epifisário) (Figuras 2 e 3A). A epífise tibial esquerda, isolada do restante da tíbia após a fratura, permaneceu articulada com o tarso, na porção distal mais preservada da articulação tíbio tarsal (Figura $3 \mathrm{C}$ ). Ao corte do tecido subcutâneo e musculatura regional, observaram-se múltiplas áreas irregulares ora vermelhas intensas, ora enegrecidas a marrom avermelhadas, por vezes, friáveis; havia dezenas de petéquias, equimoses e sufusões, associadas a moderado edema e coágulos de fibrina. No tecido subcutâneo e na musculatura adjacente, havia intensa necrose hemorrágica focalmente extensa (com cerca de 52 $\mathrm{cm}$ ), associada a hematoma subcutâneo em organização (Figuras 3B e 3D). $\mathrm{Na}$ medula óssea da tíbia adjacente ao ponto de fratura, observou-se dezenas de petéquias e equimoses. Adicionalmente, havia na face lateral dos membros anterior ENCICLOPÉDIA BIOSFERA, Centro Científico Conhecer - Goiânia, v.11 n.22; p.1337 2015 
direito e posterior direito múltiplas escoriações e escaras de decúbito medindo desde poucos milímetros até $9,0 \times 7,5 \mathrm{~cm}$ (Figura 2).

Durante a necropsia foram colhidos fragmentos de pele, tecido subcutâneo, musculatura esquelética, tíbia e dos principais órgãos. Esse material foi fixado em formol a $10 \%$ tamponado com fosfato. Os fragmentos da tíbia foram descalcificados em solução de ácido fórmico a $20 \%$, por cerca de duas semanas. Posteriormente, os fragmentos foram clivados, desidratados em álcool etílico absoluto, diafanizados em xilol, incluídos em parafina e cortados em micrótomo à espessura de $5 \mu \mathrm{m}$. Os cortes foram corados pela hematoxilina-eosina $(\mathrm{HE})$ e as lâminas examinadas em microscópio óptico.

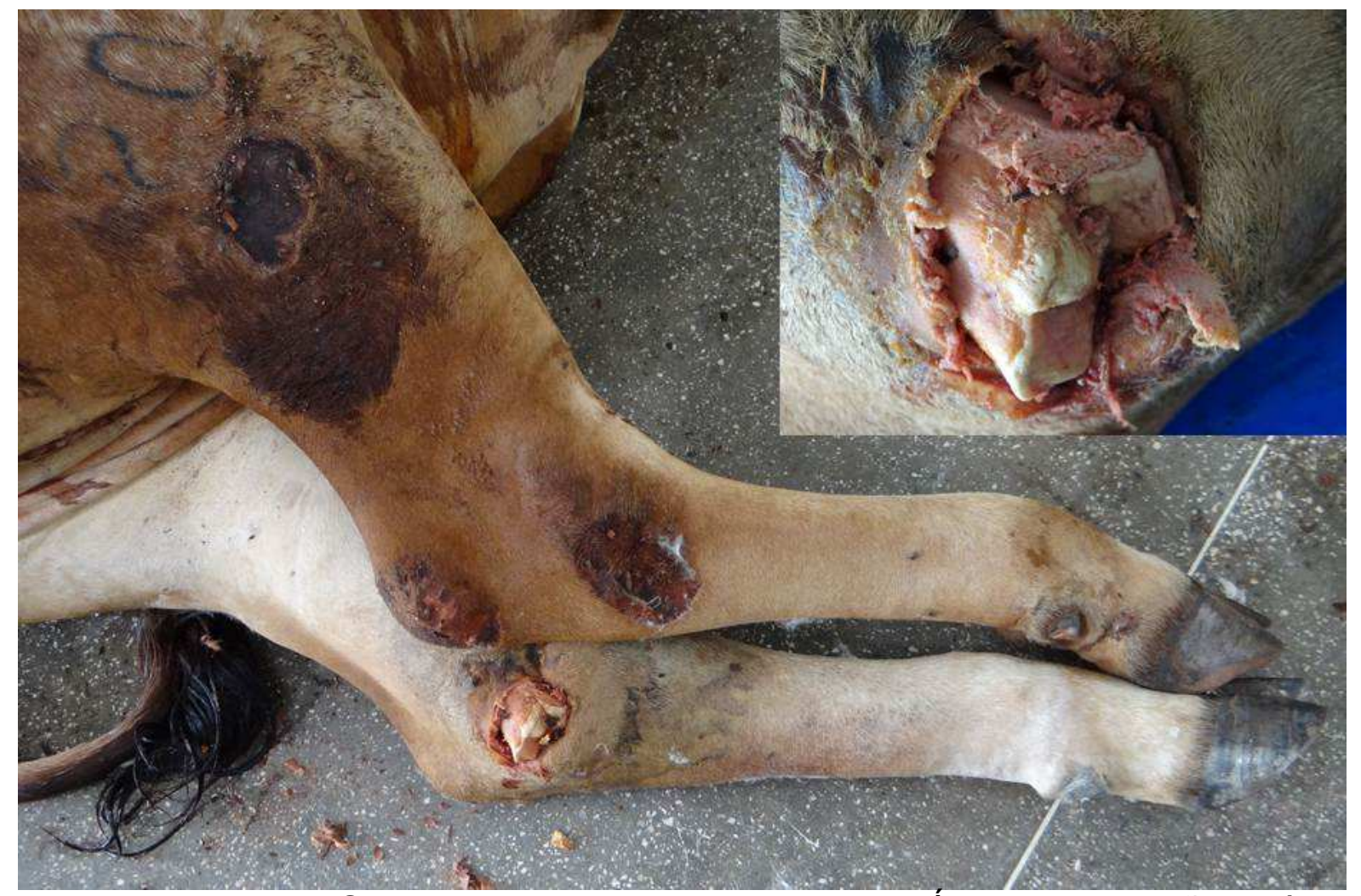

FIGURA 2: Fratura Salter Harris tipo I tibial em novilha. Área de laceração cutânea com exposição parcial da extremidade distal da diáfise e metáfise tibial esquerda. Notar em escaras de decúbito em membro pélvico direito. No detalhe, aspecto macroscópico aproximado da fratura. (Fonte: arquivo pessoal). 


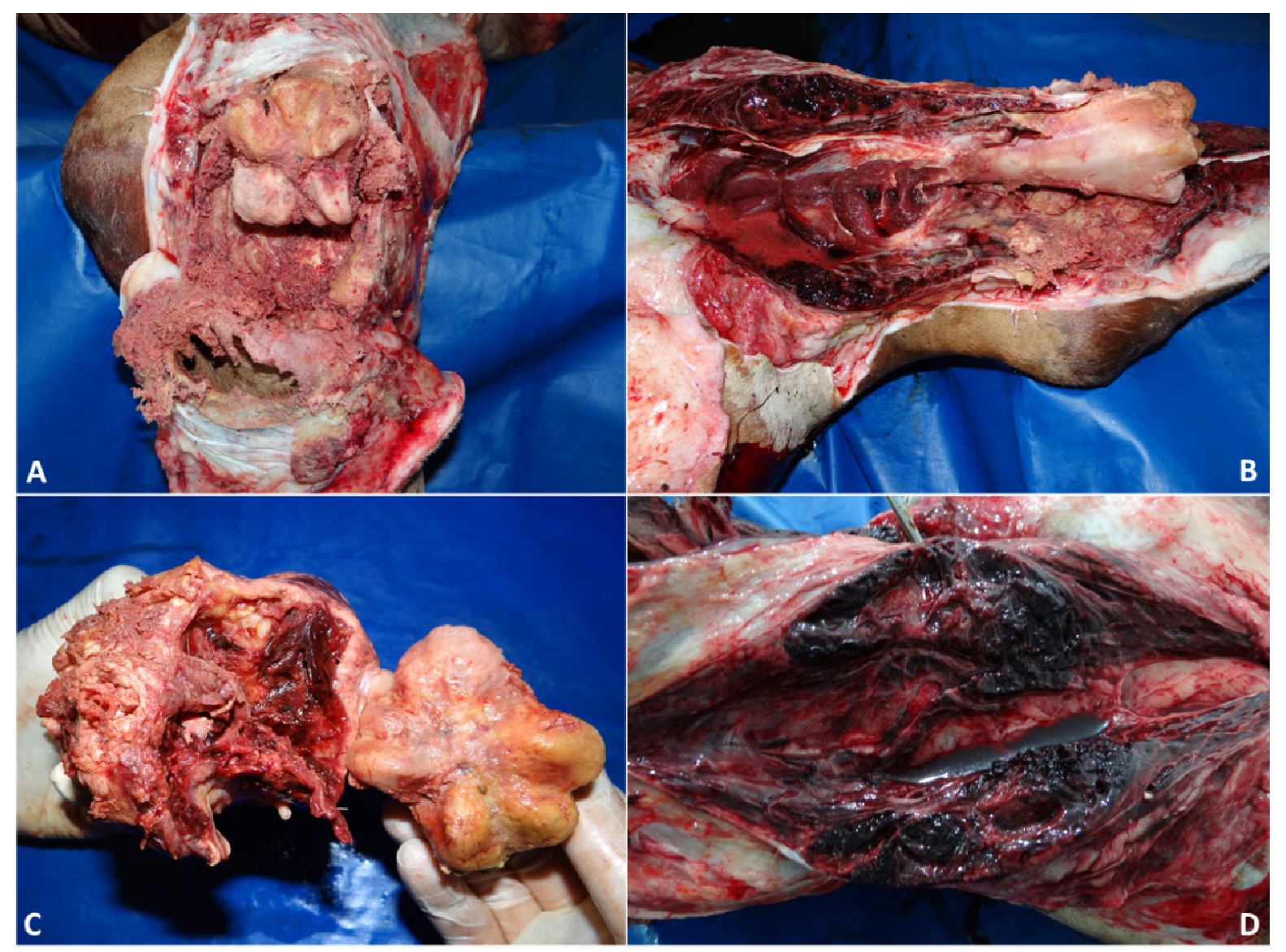

FIGURA 3: Aspecto macroscópico da fratura Salter Harris tipo I tibial em novilha. A e B. Ruptura da cápsula articular com exposição completa da extremidade distal da diáfise e metáfise tibial (fratura transversa completa através da linha de fechamento epifisário). C. Epífise tibial (a esquerda) isolada da extremidade distal da diáfise e metáfise da tíbia do MPE (a direita). B e D. Musculatura adjacente ao ponto de fratura exibindo intensa necrose hemorrágica focalmente extensa com cerca. (Fonte: arquivo pessoal).

A avaliação histopatológica evidenciou necrose óssea difusa da extremidade distal da diáfise na tíbia. Na pele, tecido subcutâneo e musculatura esquelética verificaram-se extensas áreas de necrose, associadas à acentuada hemorragia e a moderado edema intersticial com pequena quantidade de filamentos de fibrina. Observou-se ainda, na superfície da lesão áreas ulceradas contendo centenas de miríades bacterianas intralesionais, moderado infiltrado inflamatório predominantemente polimorfonuclear. Adicionalmente, havia focos de angiogênese e proliferação de tecido conjuntivo. Nos demais órgãos, não foram observadas alterações microscópicas dignas de nota.

\section{DISCUSSÃO}

O diagnóstico de fraturas em membros deve ser fundamentado no histórico de trauma e pelos sinais clínicos, que incluem aumento de volume local (edema), dor e claudicação, sendo os exames de imagem, especialmente, o radiográfico uma ferramenta diagnóstica essencial para confirmação das lesões ósseas, bem como para determinação da extensão e localização exata das lesões, o que possibilita a obtenção do prognóstico e auxilia a definição do protocolo terapêutico. 
Entretanto, a utilização do exame radiográfico na rotina da clínica de animais de produção ainda é pequena, o que se deve, em parte, a dificuldade de acessibilidade desse recurso no campo. Tal realidade difere do que ocorre na clínica de pequenos animais, cujo custo relativamente reduzido desse exame e o fácil acesso (RODRIGUES, 2011) em clínicas veterinárias, favorece o emprego em pacientes com suspeita de fraturas. Além disso, na rotina clínica de animais de companhia, a cada ano tem aumentado à investigação diagnóstica através de tomografia computadorizada e ressonância magnética (LAER, 2004), ferramentas muito úteis, mas ainda muito longe de serem empregadas, em termos práticos, na rotina diagnóstica em animais de produção. Contudo, fica evidente o valor da necropsia a campo, quando da morte de animais, para a confirmação diagnóstica de lesões músculo esqueléticas, sobretudo, daquelas fechadas (não bem evidentes durante o exame físico).

No presente caso, o diagnóstico de fratura Salter Harris tipo I tibial foi estabelecido com base nos dados clínico-epidemiológicos e confirmado pelos exames radiográficos. Adicionalmente, a avaliação necroscópica e histopatológica corroborou o diagnóstico radiográfico, confirmou o caráter necro-hemorrágico das lesões nos tecidos adjacentes secundárias à fratura e descartou-se doenças concomitantes.

Cabe ressaltar que, em bovinos a fratura Salter Harris tipo I tibial tem sido pouco relatada. No presente caso, o elevado peso corporal $(500 \mathrm{~kg})$ e a idade (dois anos) foram considerados fatores predisponentes para o desenvolvimento da fratura, que ocorreu quando o animal resvalou na propriedade. Em crianças, fraturas da placa de crescimento, geralmente, ocorrem em torno dos sete a 15 anos de idade, durante o pico de crescimento e o tipo de fratura fisária mais observada é a Salter Harris I (LAER, 2004).

Em estudo retrospectivo dos diagnósticos realizados pelo Laboratório de Patologia Veterinária da Universidade Federal de Santa Maria (UFSM) entre os anos de 1964-2008, com o intuito de se determinar a frequência e características epidemiológicas das doenças de bovinos da região Sul do Brasil, LUCENA et al. (2010) verificaram que, do total de 6.706 necropsias de bovinos realizadas nesse período, apenas em 50 casos $(0,75 \%)$ foram diagnosticados politraumatismo. Entretanto, nesse trabalho não foram especificados o tipo de trauma, o local da lesão, a ocorrência ou não de fratura óssea associada, bem como a classificação da fratura. Recentemente, CÂMARA et al. (2014) estudaram 22 casos de fraturas em membros $(6,2 \%)$ dos 353 ruminantes atendidos no Hospital Veterinário da Universidade Federal Rural do Semi-árido (UFERSA), entre junho de 2009 a dezembro de 2013, com a finalidade de relatar os principais locais de fraturas e determinar a eficiência dos tratamentos utilizados. Nesse estudo, observaram-se maior frequência de fratura em metacarpo ou metatarso (54,5\%), seguido por tíbia $(22,7 \%)$, fêmur $(9 \%)$, falange medial $(4,5 \%)$, úmero $(4,5 \%)$, rádio e ulna $(4,5 \%)$. Convém dizer que, na Bahia ainda se desconhece a real prevalência dos casos fraturas em ruminantes.

No Brasil, o tratamento cirúrgico (fixação externa ou interna) permanece de uso restrito a animais de alto valor zootécnico (fêmeas doadoras de embrião, animais de alta produção leiteira ou de corte e machos reprodutores) ou afetivo (ruminantes de estimação), tendo como fator limitante o valor do procedimento anestésico e de alguns materiais cirúrgicos (MARTINS et al., 2001, NÓBREGA et al., 2008, LUDTKE et al., 2012). No presente caso, por tratar-se de uma novilha com dois anos, da raça Gir e de alto valor zootécnico (recém-campeã de exposição), optou-se pelo 
tratamento com imobilização do MPE com gesso sintético Scotchcast®. Segundo ADAMS \& FESSLER (1983) a utilização do gesso sintético desde a articulação fêmur-tíbio-patelar, apresenta como vantagens, ser de fácil aplicação, poroso e leve, ter secagem rápida, grande resistência ao peso e nítida visualização do osso nas radiografias e não danificar quando submetido à umidade. Todavia, devido ao grande peso corporal da novilha e comportamento inquieto, não houve o resultado esperado, uma vez que ocorreu afrouxamento do gesso com perda da imobilidade e dificuldade de permanência em estação. Nessa ocasião, cogitou-se a utilização da muleta de Thomas, para uma melhor imobilização do membro, entretanto, o seu uso tornou-se inviável devido ao decúbito persistente.

\section{CONCLUSÃO}

O caso descrito contribui no estudo da patogenia dos casos de fratura Salter Harris tipo I em bovinos, haja à vista a escassez de relatos de fraturas fisárias nessa espécie, bem como gera informações sobre a ocorrência de doenças em bovinos no estado da Bahia, onde ainda hoje, a prevalência de enfermidades em ruminantes ainda são muito pouco conhecidas.

\section{REFERÊNCIAS}

ADAMS, S. B.; FESSLER, J. F. Treatment of radial-ulnar and tibial fractures in cattle using a modified Thomas splint-cast combination. Journal of the American Veterinary Medical Association, v. 183, p. 430-433, 1983.

ANDERSON D. E.; ST JEAN, G. Management of fractures in field settings. Veterinary Clinics of North America: Food Animal Practice, v. 24, n. 3, p. 567582, 2008.

CÂMARA, A. C. L.; CALAdO, E. B.; ANTUNES, M. A. P.; OliVEIRA, C. M. M.; AFONSO, A. B.; COSTA, N. A. Tratamento conservativo e cirúrgico em 22 ruminantes com fraturas em membros. Pesquisa Veterinária Brasileira, v. 34 , n. 11, p. 1045-1050, 2014.

JOHNSON, D. L.; DURBIN, T. C. Physeal-sparing tibial eminence fracture fixation with a headless compression screw. Orthopedics, v. 35, n. 7, p. 604-608, 2012.

LAER, L. V. Pediatric fractures and dislocations. $5^{\text {th }}$, Thieme, Stuttgart, Germany, p. 518, 2004.

LUCENA, R. B.; PIEREZAN, F.; KOMMERS, G. D.; IRIGOVEN, L. F.; FIGHERA, R. A.; BARROS, C. S. L. Doenças de bovinos no Sul do Brasil: 6.706 casos. Pesquisa Veterinária Brasileira, v. 30, n. 5, p. 428-434, 2010.

LUDTKE, C. B.; CIOCCA, J. R. P.; DANDIN, T.; BARBALHO, P. C.; VILELA, J. A.; FERRARINI, C. Abate Humanitário de Bovinos. World Society for the Protection of Animals, Rio de Janeiro, RJ, p. 148, 2012.

MARTINS, E. A. N.; GALERA, P. D.; RIBAS, J. A. S.; SILVEIRA, D. Gesso sintético e pinos transcorticais na redução de fratura de tíbia em uma bezerra. Ciência Rural, v. 31 , n. 1 , p. $145-148,2001$. 
MULON, P. Y. Management of long bone fractures in cattle. In Practice, v. 35, n. 5, p. 265-271, 2013.

NOBREGA, F. S.; GIANOTTI, G. C.; ALIEVI, M. M.; BECK, C. A. C.; FERREIRA, M. P.; STEDILE, R.; DAL-BÓ, I. S.; GONZALEZ, P. C.; VOLL, J. Osteossíntese de tíbia com fixador esquelético externo em um cordeiro. Acta Scientiae Veterinariae, v. 36, n. 1, p. 55-58, 2008.

PODESZWA, D. A.; MUBARAK, S. J. Physeal fractures of the distal tibia and fibula (Salter Harris type I, II, III and IV fractures). Journal of Pediatric Orthopedics, V. 32, 2012.

REILLY, L. K.; BAIRD, A. N.; PUGH, D. G. Enfermidades do sistema musculoesquelético. In: PUGH D. G. (Ed.), Clínica de Ovinos e Caprinos. Roca, São Paulo. p. 252-286, 2005.

RODRIGUES, M. B. Diagnóstico por imagem no trauma músculo-esquelético princípios gerais. Revista de Medicina, São Paulo, v. 90, n. 4, p. 185-94, out.-dez. 2011.

SALTER, R. B.; HARRIS, W. R. Injuries involving the epiphyseal plate. American Journal of Bone Joint Surgery, v. 45, p. 587-622, 1963.

SANTILI, C.; GOMES, C. M. O.; AKKARI, M.; WAISBERG, G.; BRAGA, S. R.; LINOR JUNIOR, W.; SANTOS, F. G. Fraturas da diáfise da tíbia em crianças. Acta Ortopédica Brasileira, v. 18, n. 1, p. 44-8, 2010.

SPADETO JÚNIOR, O.; FALEIROS, R. R.; ALVES, G. E. S.; CASAS, E. B. L.; RODRIGUES, L. B.; LOIACONO, B. Z.; CASSOU, F. Falhas na utilização de poliacetal e poliamida em forma de haste intramedular bloqueada para imobilização de fratura femural induzida em bovinos jovens. Ciência Rural, v. 40, n. 4, p. 907912, 2010.

STEINER, A.; ANDERSON, D. E. Fracture management in cattle. In: ANDERSON D. E.; RINGS, D. M. Current Veterinary Therapy: food animal practice. W.B. Saunders, Philadelphia. (Eds) v. 5. p. 253- 258, 2009.

VECHIATO, T. A. F.; SIQUEIRA, R. F.; COUTINHO, A.; MARCHIONI, G. G.; KOLBER M.; PEIXOTO Jr, K. C.; TOFFOLI, P. Z.; ZANCO, N. A. Utilização de fixação externa em fratura de úmero em caprino. Arquivo Brasileiro de Medicina Veterinária e Zootecnia, v. 61, n. 5, p. 1242-1245, 2009. 